\title{
Cardioprotective effects of a ruthenium (II) Schiff base complex in diet-induced prediabetic rats
}

This article was published in the following Dove Medical Press journal: Diabetes, Metabolic Syndrome and Obesity:Targets and Therapy

\author{
Lindokuhle Patience \\ Mabuza' \\ Mlindeli Wilkinson \\ Gamede' \\ Sanam Maikoo 2 \\ Irvin Noel Booysen² \\ Phikelelani Siphosethu \\ Ngubane' \\ Andile Khathi' \\ 'Department of Human Physiology, \\ School of Laboratory Medicine \\ and Medical Sciences, College of \\ Health Sciences, University of \\ KwaZulu-Natal, Durban, South Africa; \\ ${ }^{2}$ Department of Chemistry, School \\ of Chemistry and Physics, College of \\ Agricultural, Engineering and Sciences, \\ University of KwaZulu-Natal, \\ Pietermaritzburg, South Africa
}

Correspondence: Lindokuhle Patience Mabuza

Department of Human Physiology, School of Laboratory Medicine and Medical Sciences, University of KwaZulu-Natal, Room E3-408, Private Bag X5400I, Durban, South Africa

Email 2II509843@stu.ukzn.ac.za
Background: Prediabetes and the onset of cardiovascular diseases (CVD) are strongly related. Prolonged hyperglycemia has been identified as a major contributing factor in the pathogenesis of CVD and diabetic complications. The management of hyperglycemia and prediabetes-associated vascular complications rely on pharmacotherapy and lifestyle intervention strategies. However, patients still take the conventional drugs and neglect lifestyle intervention; therefore, newer alternative drugs are required. The synthesized ruthenium Schiff base complex has been shown to have elevated biological and antidiabetic activity. Thus, the research investigated the cardioprotective effects of ruthenium (II) Schiff base complex in diet-induced prediabetic (PD) rats. Materials and methods: The rats were randomly allocated to respective groups and treated for 12 weeks. Ruthenium (15 mg/kg) was administered to PD rats once a day every third day. Blood pressure and plasma glucose were monitored throughout the study. Blood and heart tissue were collected for biochemical assays.

Results: Ruthenium complex with dietary intervention lead to reduced mean arterial blood pressure which correlated with a restored heart to body weight ratio. Additionally, there was a significant decrease in tissue malondialdehyde and increased superoxide dismutase and glutathione peroxidase concentration in both the plasma and heart tissue. Furthermore, there was a decrease in plasma triglycerides, low-density lipoprotein with an increased high-density lipoprotein concentration in ruthenium-treated rats. This was further evidenced by reduced plasma tumor necrosis factor- $\alpha$, IL- 6 , and cardiac C-reactive protein concentrations in ruthenium-treated rats. Conclusion: Ruthenium coupled with dietary intervention decreased the risk of developing cardiac injury, thus preventing CVD in prediabetes. Therefore, this complex may be a beneficial therapeutic agent in the prevention of PD cardiovascular complications.

Keywords: prediabetes, cardiovascular complications, ruthenium, dietary intervention, lipid profile, antioxidants, anti-inflammatory

\section{Introduction}

Prediabetes and the onset of cardiovascular diseases (CVD) are strongly related. ${ }^{1-4}$ Prolonged hyperglycemia has been identified as a primary contributing factor in the pathogenesis of CVD and diabetes complications. ${ }^{5}$ Most obese patients are prediabetic (PD) and insulin resistant, which is correlated with subclinical inflammation characterized by overexpression of cytokines by adipose tissue and activated macrophages. ${ }^{6,7}$ In PD patients, pro-inflammatory mediators, such as tumor necrosis factor- $\alpha$ (TNF- $\alpha$ ), IL-1, IL-6, leptin, C-reactive protein (CRP), and adiponectin are involved in signaling pathways, insulin mechanism, and endurance of inflammatory response. ${ }^{7}$ Proinflammatory mediators play a crucial role in inducing insulin resistance and type 2 
diabetes mellitus (T2DM) via involvement of oxidative stress and activation of various transcriptional-mediated molecular and metabolic pathways. ${ }^{8}$ Glucolipotoxicity induces the generation of reactive oxygen species (ROS) and oxidative stress leading to the generation of various pro-inflammatory cytokines. ${ }^{8}$ Furthermore, these cytokines invade the vessels' wall, encouraging lipid accumulation and leading to atherosclerosis and CVD. ${ }^{9,10}$ Insulin resistance encourages free fatty acid (FFA) elevation. ${ }^{11}$ Elevated FFA underline increased storage of triglycerides (TG) in tissues and lower highdensity lipoprotein (HDL) levels. ${ }^{11,12}$ In a study involving PD animals, elevated blood pressure was observed in addition to impaired endothelial vasodilation and vascular reactivity during the onset of the disease. ${ }^{13-15}$ Ruthenium complex have been synthesized and complexed with nitric oxide (NO) ligand as an NO donor and scavenger. ${ }^{16} \mathrm{NO}$ released from the ruthenium improves vasodilation. ${ }^{16}$ Antonyan et al have demonstrated that ruthenium with medicinal plant curcumin as $\mathrm{Ru}$ (II)-curcumin derivative complexes showed dipeptidyl peptidase-4 (DPP-IV) inhibitor activity; thus, the use of DPP-IV inhibitors rises the circulating levels of endogenous glucagon like pepdite-1 leading to improved insulin secretion biosynthesis and inhibiting glucagon release. ${ }^{17}$ More recently, we have shown that the ruthenium Schiff base complex ameliorate glucose metabolism and prolong the progression of T2DM. ${ }^{18,19}$ However, the cardioprotective effects of ruthenium Schiff base complex in diet-induced PD rats are unknown. Thus, the goal of this study was to investigate the protective effects of novel ruthenium Schiff base complex on cardiovascular complications in diet-induced PD rats.

\section{Materials and methods}

\section{Synthesis of ruthenium (II) Schiff base complex}

The ruthenium (II) Shiff base complex, [Ru$\left.{ }^{\mathrm{II}}\left(\mathrm{H}_{3} \mathrm{ucp}\right) \mathrm{Cl}\left(\mathrm{PPh}_{3}\right)\right]$ ( $\mathrm{H}_{4} \mathrm{ucp}=2,6$-bis-((6-amino-1,3-dimethyluracilimino)methylene)pyridine) was synthesized in our laboratory as previously reported. ${ }^{20}$ The complex was then characterized by the following conductance measurements: UV/Vis, nuclear magnetic resonance, electron spin resonance, and infrared resonance spectroscopy as well as single crystal X-ray diffraction. Previous studies showed that the dose of the ruthenium complex used in this study was nontoxic.

\section{Animals and housing}

In this study, 36 male Sprague-Dawley rats (150-180 g) were used. The animals were housed in a room with a 12 hours light $/ 12$ hours dark cycle and room temperature $\left(25^{\circ} \mathrm{C}\right)$ for the duration of the study. The animals in each group had access to food and water ad libitum. All procedures and conditions were carried out according to the Animal Research Ethics Committee of the University of KwaZulu-Natal. The committee approved all animal experiments (ethics no: AREC/038/016M).

\section{Experimental design}

The induction of prediabetes was according to previous research protocol. ${ }^{18}$ After 20 weeks of induction, the oral glucose tolerance test was used to determine prediabetes according to the American Diabetes Association criteria. Fasting blood glucose (FBG) level were measured 5 days after 20 weeks of induction. The rats with the FBG of $>5.6 \mathrm{mmol} / \mathrm{L}$ were considered PD and grouped further for pharmacological studies. The treatment started on the subsequent day and this was considered as the first day of treatment. The study consisted of two main groups, the non-prediabetic animals (NPD, n=6) and the PD animals $(n=30)$. After 20 weeks, the PD animals were divided into the following groups. The first was PD group fed on high fat high carbohydrate (HFHC) diet without treatment. The second group $(\mathrm{MTF}+\mathrm{HFHC})$ was fed on HFHC diet and treated with oral dose of metformin (MTF; $500 \mathrm{mg} / \mathrm{kg}$, Sigma-Aldrich Co., St Louis, MO, USA). The third group (MTF + ND) was fed on normal diet (ND) and treated with MTF. The forth group (ruthenium $[\mathrm{RU}]+\mathrm{HFHC}$ ) was fed on HFHC diet and treated with intramuscular injection of ruthenium complex $(15 \mathrm{mg} / \mathrm{kg})$ while the fifth group (RU + ND) was fed on ND and treated with ruthenium. The animals were treated once a day every third day at 09:00 am for 12 weeks. Over the 12 week treatment period, parameters such as body weight, food intake, FBG, and blood pressure were measured every 4 weeks.

\section{Blood collection and tissue harvesting}

All animals were anesthetized with Isofor $(100 \mathrm{mg} / \mathrm{kg}$; Safeline Pharmaceuticals [Pty] Ltd, Roodepoort, South Africa) using a gas anesthetic chamber (Biomedical Resource Unit, University of KwaZulu-Natal, Durban, South Africa) for 3 minutes. Blood was collected by cardiac puncture and then injected into individual precooled heparinized containers. The blood was then centrifuged for plasma collection (Eppendorf centrifuge 5403 , Germany) at $4^{\circ} \mathrm{C}, 503 \mathrm{~g}$ for 15 minutes. The heart was also collected and stored in a BioUltra freezer (Snijders Scientific, Tilburg, Netherlands) at $-80^{\circ} \mathrm{C}$ until biochemical assays were done.

\section{Biochemical analysis}

Plasma total cholesterol (TC), TG, and HDL concentrations were measured by the Global Clinical and Viral Laboratory 
(Amanzimtoti, South Africa). Low-density lipoprotein (LDL) concentrations were calculated using Friedewald's equation. Cardiac CRP, plasma IL-6, TNF- $\alpha$, superoxide dismutase (SOD), and glutathione peroxidase (GPx) were analyzed using separate, specific ELISA kits in accordance with the manufacturer's instructions (Elabscience and Biotechnology, Wuhan, China), while heart tissue malondialdehyde (MDA) levels were measured according to a previous research protocol. ${ }^{15}$

\section{Statistical analysis}

Data are reported as mean \pm SD. GraphPad Prism Software (version 5) was used to conduct statistical analysis. The differences between control and treated groups were analyzed using one-way ANOVA followed by Tukey-Kramer. Values of $P<0.05$ show statistical significance between the compared groups.

\section{Results}

\section{Mean arterial pressure (MAP) measurements}

Figure 1 shows MAP of NPD, PD, and PD-treated animal groups monitored at week 0 and week 12 . The PD and the PD-treated groups started with the same increased MAP (week 0) before treatment (Figure 1). When compared with the NPD group, there was a significant rise in MAP of the $\mathrm{PD}$ group to the end of the experimental period $(P<0.05$; Figure 1). However, in comparison with the PD group, there was a significant reduction in MAP upon administering RU $(15 \mathrm{mg} / \mathrm{kg}$ ) coupled with both HFHC and ND in the PDtreated animals $(P<0.05$; Figure 1$)$. In addition, a similar effect was observed in the MTF $(500 \mathrm{mg} / \mathrm{kg})$ treated animals $(P<0.05$; Figure 1).

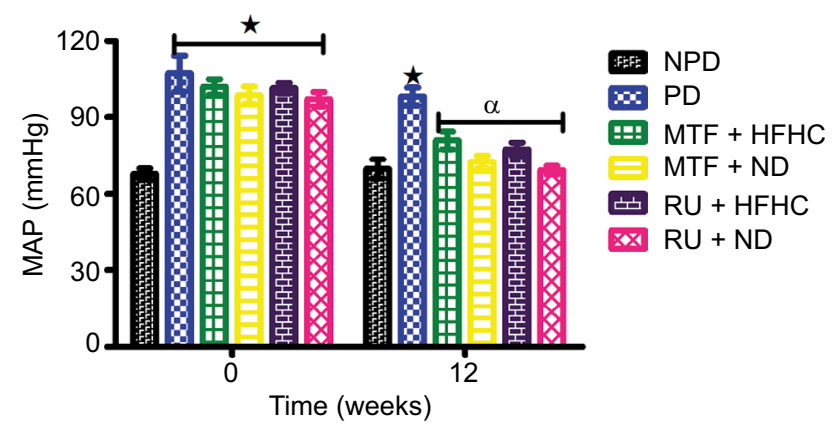

Figure I The effects of ruthenium complex on MAP of PD animals for a treatment period of 12 weeks.

Note: *, $P<0.05$ compared to NPD; $\alpha, P<0.05$ compared to PD.

Abbreviations: HFHC, high fat high carbohydrate; MAP, mean arterial pressure; MTF, metformin; ND, normal diet; NPD, non-prediabetic; PD, prediabetes; RU, ruthenium.

\section{Heart: body weight ratio}

Table 1 shows heart to body weight ratios at 12 weeks treatment period of NPD, PD, and PD-treated animal groups. When compared with the NPD group, the PD group showed a significant decrease in heart:body weight ratio $(P<0.05$; Table 1). Interestingly, when compared with the PD group, administration of RU ( $15 \mathrm{mg} / \mathrm{kg})$ along with both HFHC and ND showed a significant increase in heart:body weight ratio in the PD-treated animals $(P<0.05$; Table 1$)$. In addition, the MTF $(500 \mathrm{mg} / \mathrm{kg})$ treated animals displayed similar results $(P<0.05$; Table 1$)$.

\section{Lipid profile measurements}

Table 2 shows plasma TC, TG, HDL, and LDL concentrations of NPD, PD, and PD-treated groups at 12 weeks treatment period (Table 2). Induction of prediabetes led to insignificant increases in TG and LDL, and reduced HDL concentrations in the PD group compared with NPD group $(P<0.05$; Table 2). However, administration of RU (15 mg/kg) coupled with both HFHC and ND displayed a significantly reduced TG and LDL, and increased HDL concentrations when compared with PD group $(P<0.05$; Table 2$)$. In contrast, MTF + HFHC $(500 \mathrm{mg} / \mathrm{kg})$ treated group resulted in a further increase in TG concentration when compared with PD group $(P<0.05$; Table 2).

\section{TNF- $\alpha$ measurements}

Figure 2 shows TNF- $\alpha$ concentration of NPD, PD, and PD-treated animal groups, which was measured during the terminal study (Figure 2). When compared with the NPD group, the PD group displayed a significant increase in plasma TNF- $\alpha$ concentration $(P<0.05$; Figure 2$)$. Interestingly, administration of RU + ND (15 mg/kg) displayed a

Table I The effects of ruthenium complex on heart:body ratio of PD animals for a treatment period of 12 weeks

\begin{tabular}{|l|l|l|l|}
\hline Groups & $\begin{array}{l}\text { Body } \\
\text { weight (g) }\end{array}$ & $\begin{array}{l}\text { Heart } \\
\text { weight (g) }\end{array}$ & $\begin{array}{l}\text { Heart:body } \\
\text { ratio (\%) }\end{array}$ \\
\hline NPD & $388 \pm 0.063$ & $1.56 \pm 0.20$ & $0.40 \pm 0.063$ \\
PD & $680 \pm 0.088^{\mathrm{a}}$ & $1.72 \pm 0.17^{\mathrm{a}}$ & $0.27 \pm 0.15^{\mathrm{a}}$ \\
MTF + HFHC & $501 \pm 0.056^{\mathrm{a}, \mathrm{b}}$ & $1.7362 \pm 0.088^{\mathrm{a}}$ & $0.35 \pm 0.086^{\mathrm{a}, \mathrm{b}}$ \\
MTF + ND & $443 \pm 0.039^{\mathrm{b}}$ & $1.62 \pm 0.039^{\mathrm{a}, \mathrm{b}}$ & $0.37 \pm 0.080^{\mathrm{b}}$ \\
RU + HFHC & $490 \pm 0.059^{\mathrm{a}, \mathrm{b}}$ & $1.53 \pm 0.16^{\mathrm{b}}$ & $0.31 \pm 0.12^{\mathrm{a}, \mathrm{b}}$ \\
RU + ND & $435 \pm 0.026^{\mathrm{b}}$ & $1.51 \pm 0.11^{\mathrm{b}}$ & $0.35 \pm 0.063^{\mathrm{b}}$ \\
\hline
\end{tabular}

Notes: Values are presented as means $\pm S D(n=6)$ in each group. ${ }^{a}<<0.05$ compared to NPD, ${ }^{b}<<0.05$ compared to PD.

Abbreviations: HFHC, high fat high carbohydrate; MTF, metformin; ND, normal diet; NPD, non-prediabetic; PD, prediabetes; RU, ruthenium. 
Table 2 The effects of ruthenium complex on lipid profile of PD animals for a treatment period of 12 weeks

\begin{tabular}{|l|l|l|l|l|}
\hline Groups & TC (mmol/L) & TG (mmol/L) & HDL (mmol/L) & LDL (mmol/L) \\
\hline NPD & $4.04 \pm 0.078$ & $1.22 \pm 0.062$ & $1.70 \pm 0.052$ & $2.40 \pm 0.090$ \\
PD & $4.43 \pm 0.10$ & $3.34 \pm 0.42^{\mathrm{a}}$ & $0.85 \pm 0.024^{\mathrm{a}}$ & $5.93 \pm 0.15^{\mathrm{a}}$ \\
MTF + HFHC & $4.04 \pm 0.031$ & $5.62 \pm 0.44^{\mathrm{a}}$ & $0.77 \pm 0.080^{\mathrm{b}}$ & $8.88 \pm 0.086^{\mathrm{a}, \mathrm{b}}$ \\
MTF + ND & $4.09 \pm 0.048$ & $0.91 \pm 0.10^{\mathrm{b}}$ & $1.92 \pm 0.03 \mathrm{I}^{\mathrm{b}}$ & $1.88 \pm 0.080^{\mathrm{b}}$ \\
RU + HFHC & $4.17 \pm 0.062$ & $1.87 \pm 0.27^{\mathrm{a}, \mathrm{b}}$ & $0.63 \pm 0.040^{\mathrm{a}, \mathrm{b}}$ & $4.42 \pm 0.10^{\mathrm{a}, \mathrm{b}}$ \\
RU + ND & $4.11 \pm 0.062$ & $1.17 \pm 0.024^{\mathrm{b}}$ & $2.09 \pm 0.020^{\mathrm{b}}$ & $2.05 \pm 0.10^{\mathrm{b}}$ \\
\hline
\end{tabular}

Notes: Values are presented as mean $\pm S D(n=6)$ in each group. ${ }^{a} P<0.05$ compared to NPD; ${ }^{b} P<0.05$ compared to $P D$.

Abbreviations: HDL, high-density lipoprotein; HFHC, high fat high carbohydrate; LDL, low-density lipoprotein; MTF, metformin; ND, normal diet; NPD, non-prediabetic; PD, prediabetes; RU, ruthenium; TC, total cholesterol; TG, triglycerides.

significant decrease in plasma TNF- $\alpha$ concentration when compared with PD group $(P<0.05$; Figure 2$)$. In addition, $\mathrm{MTF}+\mathrm{ND}(500 \mathrm{mg} / \mathrm{kg})$ group exhibited similar results when compared with PD group $(P<0.05$; Figure 2$)$.

\section{IL-6 measurements}

Figure 3 shows IL- 6 concentration of NPD, PD, and PDtreated groups at 12 weeks treatment period (Figure 3). Induction of prediabetes resulted in significantly increased plasma IL-6 concentrations when compared with NPD group $(P<0.05$; Figure 3$)$. Interestingly, administration of RU (15 $\mathrm{mg} / \mathrm{kg}$ ) coupled with both HFHC and ND attenuated the PDassociated increases of plasma IL-6 concentration to within range of the NPD group. In addition, the same effect was observed in the MTF $(500 \mathrm{mg} / \mathrm{kg})$ treated groups $(P<0.05$; Table 3; Figure 3).

\section{CRP measurements}

Figure 4 shows cardiac CRP concentration of NPD, PD, and PD-treated animal groups, which was measured during the terminal study (Figure 4). Induction of prediabetes resulted in significantly increased heart CRP concentrations when compared with NPD group $(P<0.05$; Figure 4$)$. Interestingly, administration of RU $(15 \mathrm{mg} / \mathrm{kg})$ coupled with HFHC and ND attenuated the prediabetes-associated increases in heart CRP concentration when compared with NPD group. In addition, MTF $(500 \mathrm{mg} / \mathrm{kg})$ treated groups showed similar results $(P<0.05$; Figure 4$)$.

\section{MDA and antioxidants measurements}

Table 3 shows MDA and SOD and GPx concentrations in heart tissue of NPD, PD, and PD-treated groups at 12 weeks treatment period (Table 3). Induction of prediabetes resulted in a significantly increased MDA concentration and decreased SOD and GPx concentrations compared with NPD group ( $P<0.05$; Table 3). Interestingly, administration of RU + ND $(15 \mathrm{mg} / \mathrm{kg})$ attenuates the PD-associated increased MDA

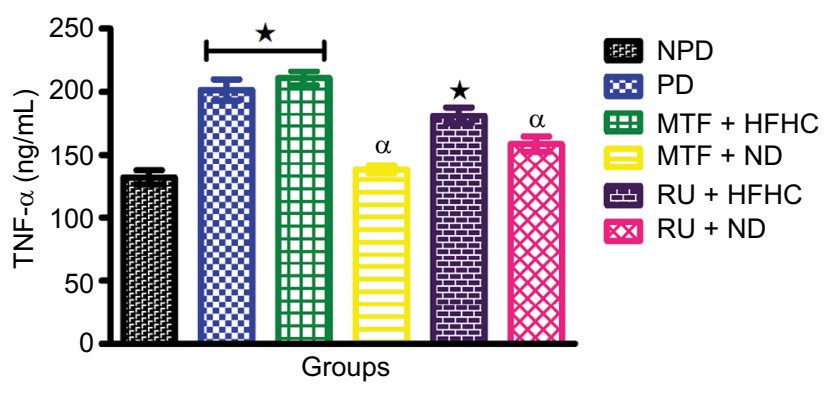

Figure 2 The effects of ruthenium complex on TNF- $\alpha$ concentration of PD animals for a treatment period of 12 weeks.

Note: *, $P<0.05$ compared to NPD; $\alpha, P<0.05$ compared to PD.

Abbreviations: HFHC, high fat high carbohydrate; MTF, metformin; ND, normal diet; NPD, non-prediabetic; PD, prediabetes; RU, ruthenium; TNF- $\alpha$, tumor necrosis factor- $\alpha$.

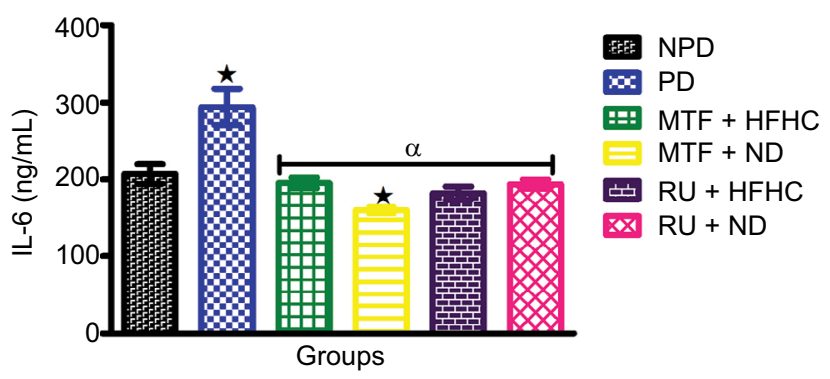

Figure 3 The effects of ruthenium complex on IL-6 concentration of PD animals for a treatment period of 12 weeks.

Note: $*, P<0.05$ compared to NPD; $\alpha, P<0.05$ compared to PD.

Abbreviations: HFHC, high fat high carbohydrate; MTF, metformin; ND, normal diet; NPD, non-prediabetic; PD, prediabetes; RU, ruthenium.

concentration in PD-treated group, while compensating the decreased SOD and GPx concentrations in PD rats to within NPD group $(P<0.05$; Table 3$)$. In addition, MTF $(500 \mathrm{mg} / \mathrm{kg})$ treated groups displayed a similar trend $(P<0.05$; Table 3$)$.

\section{Discussion}

The induction of prediabetes by the HFHC diet resulted in hyperglycemia, as stated in the previous studies. ${ }^{15,18,19}$ Chronic hyperglycemia is known as the primary contributing factor 
Table 3 The effects of ruthenium complex on oxidative stress and antioxidants of PD animals for a treatment period of 12 weeks

\begin{tabular}{|l|l|l|l|}
\hline Groups & $\begin{array}{l}\text { MDA } \\
\text { (nmol/g } \\
\text { tissue) }\end{array}$ & $\begin{array}{l}\text { SOD }(\mathbf{n g} / \\
\mathbf{m L})\end{array}$ & GPx (ng/mL) \\
\hline NPD & $0.62 \pm 0.026$ & $71.95 \pm 0.042$ & $\mathrm{I}, 780.14 \pm 0.042$ \\
PD & $1.01 \pm 0.028^{\mathrm{a}}$ & $66.42 \pm 0.052^{\mathrm{a}}$ & $\mathrm{I}, 617.24 \pm 0.072^{\mathrm{a}}$ \\
MTF + HFHC & $0.65 \pm 0.044^{\mathrm{b}}$ & $68.76 \pm 0.046$ & $\mathrm{I}, 676.30 \pm 0.046^{\mathrm{b}}$ \\
MTF + ND & $0.54 \pm 0.036^{\mathrm{b}}$ & $72.26 \pm 0.040^{\mathrm{b}}$ & $\mathrm{I}, 842.29 \pm 0.040^{\mathrm{b}}$ \\
RU + HFHC & $0.72 \pm 0.020^{\mathrm{a}, \mathrm{b}}$ & $70.25 \pm 0.046^{\mathrm{b}}$ & $\mathrm{I}, 763.14 \pm 0.07 \mathrm{I}^{\mathrm{b}}$ \\
RU + ND & $0.57 \pm 0.020^{\mathrm{b}}$ & $72.8 \mathrm{I} \pm 0.07 \mathrm{I}^{\mathrm{b}}$ & $\mathrm{I}, 826.80 \pm 0.046^{\mathrm{b}}$ \\
\hline
\end{tabular}

Notes: Values are presented as mean \pm SD $(n=6)$ in each group. ${ }^{a} P<0.05$ compared to NPD, ${ }^{b}<0.05$ compared to PD.

Abbreviations: GPx, glutathione peroxidase; HFHC, high fat high carbohydrate MDA, malondialdehyde; MTF, metformin; ND, normal diet; NPD, non-prediabetic; $\mathrm{PD}$, prediabetes; RU, ruthenium; SOD, superoxide dismutase.

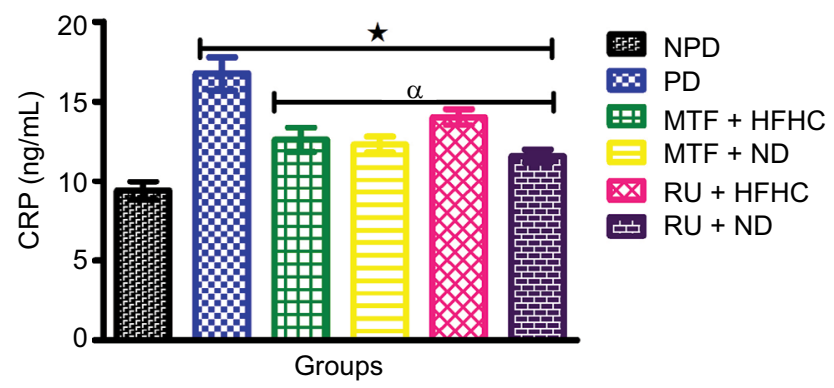

Figure 4 The effects of ruthenium complex on CRP concentration of PD animals for a treatment period of 12 weeks.

Note: *, P<0.05 compared to NPD; $\alpha, P<0.05$ compared to PD.

Abbreviations: CRP, C-reactive protein; HFHC, high fat high carbohydrate; MTF, metformin; ND, normal diet; NPD, non-prediabetic; PD, prediabetes; RU, ruthenium.

in the pathogenesis of diabetic complications. ${ }^{21}$ Recently, researchers have shown that hyperglycemia induces ROS production, which activates several pathways. ${ }^{22,23}$ Additionally, hyperglycemia-induced increases in electron transfer donors (NADH and FADH2) enhance electron flux through the mitochondrial electron transport chain, which further results in greater production of ROS, thus causing oxidative stress. ${ }^{24}$ However, to evaluate the effects of ruthenium complex on oxidative stress in the diet-induced PD rats, we evaluated the levels of an oxidative stress marker MDA. ${ }^{25}$ The administration of a ruthenium complex along with dietary intervention presented a declined MDA concentration in PD-treated group suggesting an improved glycemic control. Moreover, living organisms have their own way of defense from oxidative stress through the production of antioxidant enzymes..$^{25,26}$ Therefore, the results obtained were further evidenced by increases in SOD and GPx concentrations in the PD ruthenium-treated rats, suggesting that ruthenium complex composite the for- mation of ROS and the production of the antioxidant defense enzymes. ${ }^{26}$ In addition, increased ROS production through advanced glycation end products (AGEs) which manifest subsequent endothelial dysfunction may elucidate the reduced coronary blood flow reserve and exacerbate hypertension. ${ }^{23,27}$

During PD, hypertension may be present at the onset of the disease. ${ }^{28,29}$ The sympathetic nervous system overactivity exacerbates elevated blood pressure. ${ }^{29}$ The effects of insulin resistance on NO pathway, smooth muscle growth, sodium and fluid retention, and the excitatory effect of hyperglycemia on the renin-angiotensin-aldosterone system are plausible mechanisms that increase blood pressure in PD patients. ${ }^{30}$ Furthermore, impaired kidney function in diabetic patients has been shown to further increase blood pressure due to fluid retention. ${ }^{30}$ In the current study, high MAP resulting in elevated blood pressure in PD rats throughout the 12-week experimental period was observed. These changes were stabilized in PD rats treated with the ruthenium complex coupled with dietary intervention. These findings can be ascribed to the metal complex along with dietary intervention improving insulin sensitivity as insulin regulates sympathetic nerve activity. ${ }^{31}$ We speculate that the mechanism by which the novel ruthenium (II) Schiff base complex corrected hemodynamic alterations observed was mostly due to anti-inflammatory and antioxidant effects leading to increased NO bioavailability. ${ }^{16,32}$ Ruthenium complexes such as trans- $\left[\mathrm{Ru}\left(\mathrm{NH}_{3}\right)_{4} \mathrm{P}(\mathrm{OEt})_{3}(\mathrm{NO})\right](\mathrm{PF} 6)_{3}$ have been shown to have similar antihypertensive activity but reduced toxicity in animal work. ${ }^{33}$ Trans-[RuII(cyclam)(NO)Cl(PF6) has shown prolonged antihypertensive activity and controlled NO released in hypertensive rats. ${ }^{30,34}$

Indeed, as in PD, hyperglycemia, hyperinsulinemia, and hyperlipidemia lead to cellular and molecular changes ultimately resulting in cardiac functional and structural impairment. ${ }^{35-37}$ Systolic and diastolic dysfunctions are related with diabetic cardiomyopathy, particularly in the left ventricle. ${ }^{14}$ The results obtained showed a decreased heart weight to body weight ratio in the PD group that was convoyed by an increase in final body weight. ${ }^{14,36}$ However, treatment with a ruthenium complex and dietary intervention showed a restoration of heart to body weight ratio to within normal control group in the PD-treated group. In addition, the final body weight of ruthenium along with dietary intervention-treated rats was significantly improved, and obesity was reversed. The results obtained can be attributed to the ability of the ruthenium complex to facilitate glycemic and hemodynamic control.

Lipid profile derangement in HFHC diet-induced PD rats has been previously stated. ${ }^{15}$ Dyslipidemia in the HFHC diet-induced PD rats showed worsened cardiovascular com- 
plications possibly due to increased TG, small and dense LDL cholesterol levels, and decreased HDL cholesterol levels. With such lipoproteins modifications, these lead to aggressive atherosclerosis. ${ }^{38,39}$ In the liver, the metabolism of fructose ultimately turns into TG. ${ }^{39}$ Therefore, excessive fructose consumption can lead to rapid increase in TG synthesis levels and worsen CVD. ${ }^{40}$ Interestingly, ruthenium-treated rats had reduced TG and LDL cholesterol levels to within normal range. We hypothesize that these observations can be attributed to this metal complex stimulating lipoprotein lipase while simultaneously inhibiting hormone-sensitive lipase enzymes. The reduced TG and LDL cholesterol levels may also be due to ruthenium complex ameliorating insulin sensitivity. ${ }^{18}$ Furthermore, administering ruthenium complex showed a significant increase in HDL levels in PD-treated rats, suggesting an increased cholesterol clearance in the hepatic tissue thus, decreasing risk of CVD. ${ }^{40}$ Therefore, ruthenium complex seemed to exert a therapeutic response in ameliorating the undesired hypertriglyceridemia observed in PD patients.

PD is linked with subclinical inflammation. ${ }^{41,42}$ The high levels of circulating plasma IL-6, TNF- $\alpha$, and cardiac CRP cytokines in HFHC diet-induced PD rats represented an inflammatory response. ${ }^{6,7}$ The study evidenced that ruthenium complex along with dietary intervention can ameliorate inflammation by reducing plasma IL- 6 and TNF- $\alpha$. The results obtained can be effects of the metal complex which ameliorated insulin sensitivity and glycemic control. The transition metal copper inhibits the release of TNF- $\alpha$, IL-1, and IL-2 from macrophages by $\mathrm{Cu}$-carboxylates. They also exhibit a marked SOD-mimetic activity. ${ }^{43} \mathrm{CRP}$, another marker of inflammation, has been stated to be a good marker for predicting the risk of CVD. ${ }^{44}$ In this study, the administration of ruthenium coupled with dietary intervention lowered the concentration of CRP, and therefore lowered the risk of CVD in PD ruthenium-treated rats. Additionally, oral administration of MTF has been reported to improve endothelial function, provide protection from oxidative stress, inflammation, as well as the negative effects of angiotensin II. ${ }^{45}$ On the myocardium, MTF attenuates ischemia-reperfusion injury and prevents adverse remodeling induced by humoral and hemodynamic factors as further observed in the current study. ${ }^{46}$

\section{Conclusion}

In summary, we have found that a mononuclear ruthenium (II) diimine complex along with dietary intervention possesses cardioprotective effects in HFHC diet-induced PD rats by ameliorating oxidative stress and antioxidant defense enzymes, reducing MAP, restorating heart to body weight ratio, attenuating derangement in lipid profile, and reducting cardiac inflammatory markers. The findings of the current study, therefore, suggest that the use of this ruthenium complex could be beneficial in the management of diabetesrelated CVD. Thus, this study warrants further investigations into the molecular mechanisms of this compound on cardiovascular function.

\section{Acknowledgments}

The authors acknowledge the personnel of the Biomedical Resource Unit for their technical assistance. The National Research Foundation and College of Health Sciences at the University of KwaZulu-Natal funded this study (Grant number 106041).

\section{Author contributions}

All authors contributed toward data analysis, drafting and critically revising the paper, gave final approval of the version to be published and agree to be accountable for all aspects of the work.

\section{Disclosure}

The authors report no conflicts of interest in this work.

\section{References}

1. Movahed MR, Hashemzadeh M, Jamal MM. Diabetes mellitus is a strong, independent risk for atrial fibrillation and flutter in addition to other cardiovascular disease. Int J Cardiol. 2005;105(3):315-318.

2. Beckman JA, Creager MA, Libby P. Diabetes and atherosclerosis: epidemiology, pathophysiology, and management. JAMA. 2002;287(19):2570-2581.

3. Basu S, Yoffe P, Hills N, Lustig RH. The relationship of sugar to population-level diabetes prevalence: an econometric analysis of repeated cross-sectional data. PLoS One. 2013;8(2):e57873.

4. Rosamond W, Flegal K, Furie K, et al. Heart disease and stroke statistics - 2008 update: a report from the American Heart Association Statistics Committee and Stroke Statistics Subcommittee. Circulation. 2008;117(4):25-146.

5. Sowers JR, Epstein M, Frohlich ED. Diabetes, hypertension, and cardiovascular disease: an update. Hypertension. 2001;37(4): 1053-1059.

6. Hotamisligil GS. Inflammation and metabolic disorders. Nature. 2006;444(7121):860-867.

7. Shoelson SE, Herrero L, Naaz A. Obesity, inflammation, and insulin resistance. Gastroenterology. 2007;132(6):2169-2180.

8. Akash MSH, Rehman K, Liaqat A. Tumor necrosis factor-alpha: role in development of insulin resistance and pathogenesis of type 2 diabetes mellitus. J Cell Biochem. 2018;119(1):105-110.

9. Ferrarezi DAF, Cheurfa N, Reis AF, Fumeron F, Velho G. Adiponectin gene and cardiovascular risk in type 2 diabetic patients: a review of evidences. Arq Bras Endocrinol Metab. 2007;51(2):153-159.

10. Ait-Oufella H, Taleb S, Mallat Z, Tedgui A. Recent advances on the role of cytokines in atherosclerosis. Arterioscler Thromb Vasc Biol. 2011;31(5):969-979.

11. DeFronzo RA. Pathogenesis of type 2 diabetes mellitus. Med Clin North Am. 2004;88(4):787-835.

12. Wellen KE, Hotamisligil GS. Inflammation, stress, and diabetes. J Clin Invest. 2005;115(5):1111-1119. 
13. Turner R, Holman R, Matthews D. Hypertension in Diabetes Study (HDS): I. Prevalence of hypertension in newly presenting type 2 diabetic patients and the association with risk factors for cardiovascular and diabetic complications. J Hypertens. 1993;11(3):309-317.

14. Poornima IG, Parikh P, Shannon RP. Diabetic cardiomyopathy. Circ Res. 2006;98(5):596-605.

15. Luvuno M, Mbongwa H, Khathi A. Development of a novel prediabetes animal model using a high fat high carbohydrate diet: implications for type 2 diabetes. PLoS One. 2017;13:8-14.

16. Komers R, Anderson S. Paradoxes of nitric oxide in the diabetic kidney. Am J Physiol Renal Physiol. 2003;284(6):F1121-F1137.

17. Antonyan A, De A, Vitali LA, et al. Evaluation of (arene)Ru(II) complexes of curcumin as inhibitors of dipeptidyl peptidase IV. Biochimie. 2014;99:146-152.

18. Mabuza LP, Gamede MW, Maikoo S, Booysen IN, Ngubane PS, Khathi A. Effects of a ruthenium Schiff base complex on glucose homeostasis in diet-induced pre-diabetic rats. Molecules. 2018;23(7):1721.

19. Gamede M, Mabuza L, Ngubane P, Khathi A. The effects of plantderived oleanolic acid on selected parameters of glucose homeostasis in a diet-induced pre-diabetic rat model. Molecules. 2018;23(4):794.

20. Booysen IN, Maikoo S, Akerman MP, Xulu B. Novel ruthenium(II) and (III) compounds with multidentate Schiff base chelates bearing biologically significant moieties. Polyhedron. 2014;79:250-257.

21. Yilmaz S, Canpolat U, Aydogdu S, Abboud HE. Diabetic cardiomyopathy; summary of 41 years. Korean Circ J. 2015;45(4):266-272.

22. di Marco E, Jha JC, Sharma A, Wilkinson-Berka JL, Jandeleit-Dahm KA, de Haan JB. Are reactive oxygen species still the basis for diabetic complications? Clin Sci (Lond). 2015;129(2):199-216.

23. Seddon M, Looi YH, Shah AM. Oxidative stress and redox signalling in cardiac hypertrophy and heart failure. Heart. 2007;93(8):903-907.

24. Brownlee $M$. The pathobiology of diabetic complications: a unifying mechanism. Diabetes. 2005;54(6):1615-1625.

25. Giacco F, Brownlee M. Oxidative stress and diabetic complications. Circ Res. 2010;107(9):1058-1070.

26. Pitocco D, Tesauro M, Alessandro R, Ghirlanda G, Cardillo C. Oxidative stress in diabetes: implications for vascular and other complications. Int J Mol Sci. 2013;14(11):21525-21550.

27. Gast KB, Tjeerdema N, Stijnen T, Smit JW, Dekkers OM. Insulin resistance and risk of incident cardiovascular events in adults without diabetes: meta-analysis. PLoS One. 2012;7(12):e52036.

28. Schauer IE, Snell-Bergeon JK, Bergman BC, et al. Insulin resistance, defective insulin-mediated fatty acid suppression, and coronary artery calcification in subjects with and without type 1 diabetes: the CACTI study. Diabetes. 2011;60(1):306-314.

29. Huggett RJ, Scott EM, Gilbey SG, Stoker JB, Mackintosh AF, Mary DA Impact of type 2 diabetes mellitus on sympathetic neural mechanisms in hypertension. Circulation. 2003;108(25):3097-3101.

30. Ferrannini E, Cushman WC. Diabetes and hypertension: the bad companions. Lancet. 2012;380(9841):601-610.
31. Zhou MS, Wang A, Yu H. Link between insulin resistance and hypertension: what is the evidence from evolutionary biology? Diabetol Metab Syndr. 2014;6(1):12.

32. Oishi JC, Buzinnari TC, Pestana CR, et al. In vitro treatment with cis-[Ru(H-dcbpy- $2(\mathrm{Cl})(\mathrm{NO})]$ improves the endothelial function in aortic rings with endothelial dysfunction. J Pharm Pharm Sci. 2015;18(5):696-704.

33. Torsoni AS, de Barros BF, Toledo JC, et al. Hypotensive properties and acute toxicity of trans-[Ru(NH(3))(4)P(OEt)(3)(NO)](PF(6))(3), a new nitric oxide donor. Nitric Oxide. 2002;6(3):247-254.

34. Marcondes FG, Ferro AA, Souza-Torsoni A, et al. In vivo effects of the controlled no donor/scavenger ruthenium cyclam complexes on blood pressure. Life Sci. 2002;70(23):2735-2752.

35. Fredersdorf S, Thumann C, Zimmermann WH, et al. Increased myocardial SERCA expression in early type 2 diabetes mellitus is insulin dependent: in vivo and in vitro data. Cardiovasc Diabetol. 2012;11(1):57.

36. Hou L, Lian K, Yao M, et al. Reduction of n-3 PUFAs, specifically DHA and EPA, and enhancement of peroxisomal beta-oxidation in type 2 diabetic rat heart. Cardiovasc Diabetol. 2012;11(1):126.

37. Bugger H, Abel ED. Rodent models of diabetic cardiomyopathy. Dis Model Mech. 2009;2(9-10):454-466.

38. Renard CB, Kramer F, Johansson F, et al. Diabetes and diabetes-associated lipid abnormalities have distinct effects on initiation and progression of atherosclerotic lesions. J Clin Invest. 2004;114(5):659-668.

39. Zaman MQ, Leray V, Le Bloc'h J, Thorin C, Ouguerram K, Nguyen P. Lipid profile and insulin sensitivity in rats fed with high-fat or highfructose diets. Br J Nutr. 2011;106(Suppl 1):S206-S210.

40. Angelopoulos TJ, Lowndes J, Zukley L, et al. The effect of highfructose corn syrup consumption on triglycerides and uric acid. J Nutr. 2009;139(6):1242S-1245S.

41. Emanuela F, Grazia M, Marco de R, Maria Paola L, Giorgio F, Marco B. Inflammation as a link between obesity and metabolic syndrome. $J$ Nutr Metab. 2012;2012:476380.

42. Makki K, Froguel P, Wolowczuk I. Adipose tissue in obesity-related inflammation and insulin resistance: cells, cytokines, and chemokines. ISRN Inflamm. 2013;2013(5091):1-12.

43. Bharti S, Singh S. Metal based drugs: current use and future potential. Der Pharmacia Lettre. 2009;1(2):39-51.

44. Pradhan AD, Manson J, Rifai N, Buring J. C-reactive protein, interleukin 6 , and risk of developing type 2 diabetes mellitus. JAMA. 2001;286(3):327-334.

45. Mahrouf M, Ouslimani N, Peynet J, et al. Metformin reduces angiotensin-mediated intracellular production of reactive oxygen species in endothelial cells through the inhibition of protein kinase C. Biochem Pharmacol. 2006;72(2):176-183.

46. Nesti L, Natali A. Metformin effects on the heart and the cardiovascular system: a review of experimental and clinical data. Nutr Metab Cardiovasc Dis. 2017;27(8):657-669.

Diabetes, Metabolic Syndrome and Obesity: Targets and Therapy

\section{Publish your work in this journal}

Diabetes, Metabolic Syndrome and Obesity: Targets and Therapy is an international, peer-reviewed open-access journal committed to the rapid publication of the latest laboratory and clinical findings in the fields of diabetes, metabolic syndrome and obesity research Original research, review, case reports, hypothesis formation, expert opinion and commentaries are all considered for publication. The manuscript management system is completely online and includes a very quick and fair peer-review system, which is all easy to use. Visit http://www.dovepress.com/testimonials.php to read real quotes from published authors. 